\title{
O fenômeno da acomodação familiar em pais/mães de pacientes com transtorno obsessivo-compulsivo ${ }^{1}$
}

\author{
Parenthood and family accommodation in relatives \\ of patients with obsessive-compulsive disorder
}

\author{
Maria Cristina Lopes de Almeida AMAZONAS² \\ Renata Lopes ARCOVERDE ${ }^{3}$ \\ Marcus Túlio CALDAS² \\ Renata Raimundo da SILVA ${ }^{4}$
}

\section{Resumo}

\begin{abstract}
Um dos fenômenos mais frequentes nas famílias de pacientes com Transtorno Obsessivo-Compulsivo é a acomodação familiar: participação nos rituais do paciente e modificações na rotina, contribuindo para o desencadeamento e a manutenção dos sintomas. Nesta pesquisa, verificou-se o grau de acomodação familiar apresentado por doze mães e dois pais, selecionados por meio da aplicação da Medida de Criticismo Percebido aos pacientes. Os familiares responderam à Escala de Acomodação Familiar. Os resultados foram analisados em torno de quatro temáticas: 1) participação nos rituais obsessivo-compulsivos do(a) paciente; 2) modificações na rotina familiar; 3) desgaste na família; 4) grau de perturbação do(a) paciente quando não atendido(a) em suas solicitações. De 70 respostas, 78,6\% afirmaram a participação nos rituais obsessivo-compulsivos; de 56 respostas, 78,6\% disseram haver modificações na rotina familiar; 100,0\% das respostas indicaram desgaste na família e 83,3\% mostraram que o paciente perturba os familiares quando não é atendido em suas solicitações.
\end{abstract}

Unitermos: Ambiente familiar. Estrutura de parentesco. Transtorno obsessivo-compulsivo.

\begin{abstract}
One of the most frequent phenomena in the families of obsessive-compulsive disorder patients is Family Accommodation:participation in the patient's rituals, with modifications to the routine, which contributes to reinforcing and maintaining the symptoms. This study aimed to evaluate the level of Family Accommodation presented by 12 mothers and 2 fathers, selected from the Measure of Perceived Criticism applied to the patients. Results were analyzed according to four dimensions: 1) participation in patient's obsessive-compulsive rituals; 2) modifications to family routine; 3) family stress; 4) patient's disturbancelevel when not helped. From 70 answers (100.0\%), 78.6\% related participation in obsessive-compulsive behavior. Out of a total of 56 answers (100.0\%), 78.6\% indicated changes in family routine; $100.0 \%$ of the answers indicated family stress, and $83.3 \%$ indicate that the patient is disturbed when not helped.
\end{abstract}

Uniterms: Home environment. Kinship structure. Obsessive-compulsive disorder.

\section{$\boldsymbol{\nabla \nabla V \nabla}$}

1 Este artigo é um recorte de uma pesquisa mais ampla que deu origem à dissertação de mestrado "Um estudo sobre a relação família-paciente com transtorno obsessivo-compulsivo", defendida em 2008 por R. R. SILVA. Universidade Católica de Pernambuco.

2 Universidade Católica de Pernambuco, Curso de Mestrado em Psicologia Clínica. R. do Príncipe, 526, Bloco G4, $8^{\circ}$ andar, Setor C, Sala C4, 50050-900, Boa Vista, Recife, PE, Brasil. Correspondência para/Correspondence to: M.C.L.A. AMAZONAS.

3 Universidade Católica de Pernambuco, Curso de Psicologia. Recife, PE, Brasil.

4 Mestre em Psicologia Clínica. Recife, PE, Brasil. 
Durante a história nosográfica do Transtorno Obsessivo-Compulsivo (TOC), tem sido proposto classificá-lo ora como um transtorno afetivo, ora como uma psicose atípica. Mesmo sua categorização como transtorno de ansiedade poderia não estar correta, uma vez que seriam primárias, na verdade, as obsessões e compulsões, e não a ansiedade, como é considerado nesse grupo. Entretanto, o Manual Diagnóstico e Estatístico de Transtornos Mentais (DSM-IV) coloca-o entre os transtornos de ansiedade, como tem ocorrido tradicionalmente (American Psychiatric Association - APA, 2002).

Apesar das dificuldades acima descritas, há concordância a respeito de que suas principais características são as obsessões e compulsões. Obsessões são "ideias, pensamentos, impulsos ou imagens persistentes, que são vivenciados como intrusivos e inadequados e causam acentuada ansiedade ou sofrimento". Compulsões são"comportamentos repetitivos ... ou atos mentais ..., cujo objetivo é prevenir ou reduzir a ansiedade ou sofrimento, ao invés de oferecer prazer ou gratificação" (APA, 2002, p.399). Em diferentes graus, esses sintomas provocam sofrimento importante ou prejuízo significativo. Particularmente, é considerado critério diagnóstico o fato de consumirem mais de uma hora por dia em sua execução (APA, 2002).

Rangé (2003) elenca exemplos de sintomas associados ao TOC: lavar repetidamente as mãos ou tomar vários banhos em um mesmo dia (compulsão), por achar que se não o fizer será contaminado com germes, bactérias ou outras doenças (obsessão); verificar com muita frequência se realmente fechou o registro do gás de cozinha (compulsão), por achar que se não o fizer alguém pode se intoxicar (obsessão); guardar jornais e revistas antigos (compulsão), por achar que algum dia suas notícias poderão ser úteis (obsessão); entre outros. Também podem estar presentes rituais mentais, como contar até determinado número, mentalmente, sempre que se vê um objeto específico (compulsão), para impedir que alguém na família sofra um acidente (obsessão); ou imaginar figuras religiosas (compulsão) imediatamente após ter pensado em fantasias sexuais, para neutralizar a ideia de ser um(a) pervertido(a) (obsessão).

Algumas vezes, o paciente não se dá conta de 58 que esses pensamentos e ações são sintomas de um transtorno, havendo insight pobre, mas outras vezes essas atitudes vêm acompanhadas de sentimentos de desconforto e estranheza, havendo um reconhecimento de que aqueles pensamentos e ações são irracionais. No entanto, mesmo ocorrendo essa crítica, é comum que os portadores de TOC não consigam deixar de executar suas compulsões, pois elas anulam a ansiedade gerada pelas obsessões (Torresan, Smaira, RamosCerqueira \&Torres, 2008). Apesar de o DSM-IV não sugerir uma subdivisão em categorias clínicas, uma vez que pensamentos obsessivos e atos compulsivos apresentam-se frequentemente associados, o Código Internacional de Doenças (CID), em sua décima edição, propõe que especificar um conjunto de sintomas pode ser útil no sentido de uma indicação terapêutica mais precisa (Organização Mundial de Saúde, 1993). Apresenta-se a seguir, em linhas gerais, a proposta do CID-10 (1993):

Sob a rubrica f42.0, intitulado: "Predominantemente pensamentos obsessivos ou ruminações", estão listados pensamentos, representações mentais ou sensações de descontrole no agir, provocando a impressão de intensa impulsividade. As ruminações obsessivas se apresentam na forma de dúvidas que nunca chegam a um fim. Aparentemente se destinam a reflexões fundamentais, seja em relação a questões que se destinam a responder aos grandes temas humanos ou a descobertas científicas extraordinárias. Entretanto, examinadas com maior atenção, mostram-se banais e pouco consistentes. Têm como resultado final inibir as decisões e comportamentos necessários ao dia a dia.

No item seguinte ( 442.1 ), intitulado: "Predominantemente atos compulsivos (rituais obsessivos)", observam-se comportamentos primitivos criados pelo próprio indivíduo como forma de neutralizar ações que possam causar danos. Como não é possível determinar claramente a origem da ameaça, os rituais obsessivos terminam por condicionar grande parte do comportamento, provocando a sensação de uma extrema e complexa organização. A terapia comportamental cognitiva seria a mais indicada para tratar os sintomas desse grupo.

Algumas comorbidades são mais comumente associadas ao TOC, como Depressão Maior, Fobia Específica, Fobia Social, Transtorno de Pânico, Transtornos Alimentares ou Transtorno de Tourette. Além 
disso, é necessário distinguir o TOC do Transtorno de Personalidade Obsessivo-Compulsiva, pois este último não apresenta obsessões e compulsões, mas um padrão repetitivo de comportamento, em que há grande preocupação do indivíduo com o controle da rotina, organização extrema e perfeccionismo (DSM-IV, 2002).

Ainda com relação ao diagnóstico diferencial, o mesmo manual cita que "os pensamentos delirantes e ruminativos e os comportamentos estereotipados e bizarros que ocorrem na Esquizofrenia distinguem-se das obsessões e compulsões pelo fato de não serem egodistônicos nem sujeitos ao teste de realidade"(DSM-IV, 2002, p.340).

Estudos epidemiológicos sobre TOC na infância e adolescência ainda são raros, e um dos mais importantes foi realizado na Grã-Bretanha, onde se encontrou uma incidência de 0,25\% em pessoas entre 5 e 15 anos de idade; em adultos, estima-se um percentual em torno de 2,5\% da população (Torres \& Lima, 2005).

Na literatura psicanalítica, o TOC, chamado neurose obsessiva, tem sido compreendido como uma regressão a estágio anterior em que o ego, comprometido em seu desenvolvimento, passa a acreditar que seus pensamentos e fantasias adquiriram a capacidade de prejudicar outras pessoas. Consequentemente, a pessoa desenvolve mecanismos de defesa, dentre os quais são pontuados o isolamento, a anulação, a formação reativa e a intelectualização (Leahy, McGinn, Bush \& Milrod, 2007). Os mesmos autores apontam que entre os novos desenvolvimentos da psicanálise estão estudos que indicam que ameaças ou mesmo rupturas na relação bebê-cuidador - ou, em outra direção, a superproteção de figuras parentais - estão na raiz da agressão, culpa, tentativas de controlar a ameaça contínua de perda e, por fim, predisporiam ao pensamento mágico e aoTOC.

Para este estudo optou-se por adotar a perspectiva da Análise do Comportamento, que considera que os sintomas do TOC são resultantes de aprendizagens errôneas e que podem ser desaprendidas. Inicialmente, o medo e a aflição seriam associados a pensamentos em consequência de experiências traumáticas. Assim, esses pensamentos, até então neutros, passariam a ser considerados intrusivos (obsessões), sendo generalizados para outros objetos que tenham alguma associação com o estímulo traumático original. Em seguida, o indivíduo encontraria uma forma de neutralizar novamente os pensamentos obsessivos, por meio de rituais, comportamentos evitativos e reasseguramentos (compulsões). Desta forma, essas compulsões se tornariam repetitivas e estereotipadas devido à sua eficácia em proporcionar alívio às obsessões (Cordioli, 2004a).

Nesta perspectiva, alguns autores (Niederauer, Braga, Souza, Meyer \& Cordioli, 2007) descrevem um fenômeno chamado acomodação familiar como uma das variáveis da interação da família com o portador de TOC. A acomodação familiar é a participação direta da família nos comportamentos associados aos rituais do paciente com TOC e às modificações na rotina diária, contribuindo para o desencadeamento e a manutenção dos sintomas (Guedes, 2001).

Como exemplos de acomodação familiar, Guedes (2001, p.65) cita "desde ajudar em tarefas simples, falar infinitas vezes sobre o mesmo assunto, submeter-se a rituais de descontaminação ou organização ou mesmo se conformar com a impossibilidade de utilizar cômodos da própria casa".

Conviver diariamente com um portador de TOC pode ser exaustivo, não só porque seus rituais impõem certa rigidez ao ambiente, mas porque se torna estressante presenciar a repetição de comportamentos aparentemente sem sentido. Assim, a presença de uma pessoa com comportamentos obsessivos e compulsivos tende a produzir mudanças na vida daqueles que convivem com ela (Silva, 2008)

Estudos têm demonstrado que familiares de portadores de TOC muitas vezes reduzem suas atividades sociais, de forma a se dedicar mais a cuidar dos que estão doentes, além de terem níveis aumentados de desgaste (Ferrão, 2004).

Sukhodolsky et al. (2005), em pesquisa realizada com pais de crianças com TOC, encontraram maior flexibilidade nas regras e tomada de decisões da família. Segundo os autores, isso pode ser um indicativo de que os pais aprenderam a utilizar estratégias adaptativas para lidar com a doença, o que reforçaria os sintomas dos filhos.

Já Riquier (2004) comenta que foi encontrado um percentual de $60 \%$ de familiares que se envolveram em rituais do parente com TOC ou que tentaram evitar sua exposição a possíveis situações geradoras de ansiedade. 
Esse tipo de interferência dos familiares funciona como um reforço para os sintomas obsessivo-compulsivos, pois, ao ajudar o parente adoecido a evitar a exposição a estímulos temidos e realizar rituais neutralizadores das obsessões, é como se a família estivesse confirmando que esses comportamentos são mesmo necessários. É claro que os parentes normalmente utilizam essas estratégias na intenção de tentar reduzir o sofrimento do portador de TOC, porém o resultado disso é que a extinção natural dos medos torna-se impossível por meio da habituação, e o transtorno se perpetua (Cordioli, 2004b).

Por todas essas razões, justifica-se realizar um estudo que vise compreender o fenômeno denominado acomodação familiar; neste caso, mais especificamente, compreender como pais e mães colaboram para o desencadeamento e a manutenção dos sintomas obsessivo-compulsivos dos filhos.

Ser pai/mãe não é um processo natural: os vínculos entre pais e filhos são desenvolvidos ao longo da vida e necessitam de uma aprendizagem, tanto por parte dos pais quanto dos filhos, e nenhum dos membros se mantém passivo nesta situação. Durante todo o processo de desenvolvimento, mas principalmente na infância, hábitos são adquiridos através de aprendizagem, tanto por imitação (modelação) quanto por reforçamento e/ou punição. No caso do TOC, considera-se que o repertório de respostas do paciente é mantido, principalmente, por reforço negativo - fuga e esquiva (Guedes, 2001).

A intenção, neste estudo, foi compreender como é desempenhar a função de pai e mãe desses pacientes em relação aos sintomas da doença e ao grau de acomodação familiar. Este artigo é um recorte de um estudo mais amplo em que foi investigada a relação família-paciente com transtorno obsessivo-compulsivo. Neste, tomaram-se para a análise as respostas dos pais/mães, porque $46 \%$ dos membros da família que foram indicados pelos pacientes, no estudo mais amplo, tinham este grau de parentesco. Pode-se considerar que, em geral, são estes familiares que se encontram mais envolvidos com o tratamento dos pacientes, principalmente entre aqueles mais jovens, com um prognóstico mais promissor em termos de tratamento.

Considerando o número relativamente pequeno de autores que investigam a importância das relações familiares para a melhoria ou manutenção dos sintomas de pacientes com TOC, mais especificamente a relação dos pais com os filhos, esta pesquisa poderá trazer significativa contribuição para a literatura sobre o tema. O intuito é oferecer subsídios que propiciem uma atenção mais adequada a esses pais por parte dos profissionais que lidam com eles.

\section{Método}

Este estudo descritivo se originou de uma investigação mais ampla a respeito das relações familiares de pacientes com TOC, realizado por uma das autoras do artigo. Nessa investigação, foram contatados trinta pacientes previamente diagnosticados com TOC pelo Consórcio Nacional do Transtorno Obsessivo-Compulsivo (C-TOC). Esse diagnóstico foi feito segundo a classificação do DSM-IV e a Escala de Sintomas Obsessivo-Compulsivos de Yale-Brown, de autoria de Goodman, Rassmussen e Price, em versão traduzida para o português por Ashbar et al. e reproduzida em Cordioli (2004b). Esses pacientes indicaram, pela Medida de Criticismo Percebido (Steketee \& van Noppen, 2003), doze mães e dois pais como familiares mais próximos, além de quatro amigas, três maridos, duas esposas, duas irmãs, duas filhas, um irmão, um avô e uma noiva. A Medida de Criticismo Percebido é uma escala que questiona o paciente sobre aspectos relativos a dois familiares, eleitos por ele próprio, que coabitem com ele e que sejam maiores de idade. Neste artigo, estão descritos apenas os resultados analisados a partir dos dados coletados com os pais/mães destes pacientes.

\section{Participantes}

Os pacientes que indicaram seus familiares para tomar parte nesta pesquisa foram selecionados no Hospital Oswaldo Cruz, Recife (PE), no setor para atendimento a pacientes com TOC do Projeto do Espectro Obsessivo-Compulsivo (PROTOC). Os familiares cujas respostas foram analisadas tinham entre 51 e 60 anos de idade (42,8\%), ensino fundamental completo $(42,9 \%)$ e eram doze mães e dois pais.

\section{Instrumentos}

Os instrumentos utilizados foram a Medida de Criticismo Percebido (Steketee \& Van Noppen, 2003), 
aplicada aos pacientes com TOC, a Escala de Acomodação Familiar (Calvocoressi et al., 1995) e uma entrevista semiestruturada individual, aplicadas aos pais e às mães.

A Medida de Criticismo Percebido (Steketee \& van Noppen, 2003) é um instrumento autoaplicável composto por cinco escalas que apontam como o paciente percebe as críticas de seus familiares relativas ao TOC. Este instrumento possibilita identificar dois familiares mais próximos ao paciente, a partir de sua própria perspectiva. Na pesquisa em questão, os familiares que participaram foram os que alcançaram maiores pontuações na Medida de Criticismo Percebido.

A Escala de Acomodação Familiar de Calvocoressi et al. (1995) foi desenvolvida, testada e validada na Yale University School of Medicine, contendo originalmente doze itens. Foi utilizada, aqui, uma adaptação da versão traduzida por Maria Luísa Guedes (1997) na Universidade de São Paulo (USP), contendo treze questões acerca da influência do TOC sobre a família do paciente, modificações na organização e na rotina familiar e desgaste da família do paciente.

A entrevista semiestruturada é um instrumento para a coleta qualitativa de dados, composto por um roteiro com perguntas abertas, ou seja, sem respostas prefixadas, em que o entrevistado pode discorrer livremente sobre o tema proposto pelo entrevistador (Santos \& Candeloro, 2006). Ela foi utilizada para obter mais informações acerca de modificações na rotina familiar, desgaste na família, sintomas obsessivo-compulsivos percebidos e estratégias de enfrentamento desses sintomas. Conteve as seguintes perguntas: Como é que é para você ter uma pessoa com Transtorno Obsessivo-Compulsivo na família? Que comportamentos obsessivo-compulsivos você percebe? Como você se sente? Existiu alguma modificação na rotina familiar? Houve algum desgaste na sua família? Existe alguma consequência quando você não participa dos comportamentos obsessivo-compulsivos? Você gostaria de acrescentar algo que não Ihe foi perguntado?

\section{Procedimentos}

O projeto da investigação foi submetido e aprovado pelo Comitê de Ética em Pesquisa da Insti- tuição, protocolo 155/2006. Fez-se contato com os pacientes em tratamento, que assinaram um Termo de Consentimento Livre e Esclarecido (TCLE) após aceitarem participar da pesquisa.

Os familiares foram selecionados a partir dos resultados da aplicação aos pacientes da Medida de Criticismo Percebido, que indicou qual o familiar mais próximo de cada paciente. Após a identificação deste familiar, quando se tratava do pai ou da mãe do paciente era pedido o TCLE para participar da pesquisa. Logo depois, ele respondia à Escala de Acomodação Familiar de Calvocoressi et al. (1995).

As entrevistas foram realizadas no PROTOC, em sala reservada, para que não houvesse interrupções e para preservar o sigilo das informações repassadas. Elas foram gravadas, com autorização prévia dos sujeitos, e posteriormente transcritas na íntegra.

Os resultados receberam tratamento estatístico descritivo. Foram calculados apenas percentuais, sem necessidade de utilização de nenhum programa estatístico específico, devido ao número reduzido de participantes. As entrevistas foram submetidas à Análise de Conteúdo (Severino, 2007).

\section{Resultados e Discussão}

Os resultados obtidos pelas mães e pais na Medida de Criticismo Percebido, respondida pelos pacientes com Transtorno Obsessivo-Compulsivo, mostram que as mães dos pacientes obtiveram escores mais altos (85\%) em relação aos pais (14,2\%) nesta escala. Este dado confirma o que a literatura (Almeida, 2007; Costa, 2003) aponta em relação às figuras parentais. Embora não se possam ignorar as mudanças nos costumes, ocorridas nos últimos anos, ainda é grande a força da tradição cultural segundo a qual é a mãe o familiar que mais exerce o papel de cuidadora dos filhos. A esse respeito, Costa (2003, p.3) diz que: "ainda hoje se olha de forma preconceituosa, especialmente nos países latinos, para a participação ativa do homem na vida cotidiana da criança, em suas tarefas diárias de alimentação, vestir, o acolhimento nos momentos de dor e sofrimento, dentre outros, tarefas essas, em geral, exclusivas do feminino".

Os resultados da Escala de Acomodação Familiar aplicada aos pais e às mães receberam tratamento 
estatístico descritivo, que levou em consideração o percentual de respostas dos participantes em quatro temáticas:

1) participação nos rituais obsessivo-compulsivos do paciente (cinco questões);

2) modificações na rotina familiar (quatro questões);

3) desgaste na família (uma questão);

4) grau de perturbação do paciente quando não atendido em suas solicitações (três questões).

Quanto à participação nos rituais obsessivo-compulsivos dos filhos, os resultados mostram que das 70 respostas emitidas pelos pais e mães, apenas 21,4\% se referem a nunca participar dos comportamentos obsessivo-compulsivos dos filhos. Entre as demais respostas (78,6\%), que afirmam algum grau de atuação nestes comportamentos, 44,3\% indicam participação de três a seis vezes durante a semana e até diariamente. Isto significa um alto nível de participação. Entre as formas de tomar parte, foram encontrados: reassegurar o filho, respondendo a perguntas feitas obsessivamente, de forma a tranquilizá-lo; auxiliá-lo a evitar situações que poderiam causar ansiedade; deixar de ir a lugares e estar com pessoas por causa dos comportamentos apresentados por seu filho, entre outras situações em que os sintomas do TOC são reforçados pela família (Guedes, 2001). Uma das participantes, que percebe no filho sintomas obsessivos, diz: "Ele quer tirar a dúvida: 'mãe, eu sou gay?' E se eu disser que não, pra ele tanto faz eu dizer não, como sim. A resposta eu acho na hora, mas ele vai continuar me perguntando do mesmo jeito" (P2, mãe de S).

Esse rapaz tem pensamentos sexuais intrusivos com outros homens (obsessão), que causam grande ansiedade. Por isso, ele pergunta constantemente à mãe se é homossexual (compulsão), para que ela diga que não, já que considera que esses pensamentos são estranhos a ele. Neste caso, a mãe também mostra um comportamento frequente nestes familiares, indicando acomodação familiar: fala exaustivas vezes sobre o mesmo assunto com o filho, reforçando, desta forma, seu sintoma, embora perceba que este comportamento não faz com que ele pare de perguntar. Esta mãe não se dá conta de que ao agir deste modo o efeito é contrário àquilo que ela deseja, isto é, extinguir o comportamento

62 obsessivo do filho. Na realidade, sua atitude está reforçando ainda mais o comportamento compulsivo de perguntar do filho, pois ela está dispensando a ele atenção.

Outra paciente diz o seguinte a respeito da filha:

"Ela ficava assim, no chão, deitada, sem tomar banho, não conseguia tomar um banho. Eàs vezes quem dava o banho eraeu, eraeu que davabanho nela. Elavaivestir a roupa: veste a calcinha, ela veste e tira as calcinhas. Minha filha, faça esse negócio não com suas calcinhas. As calcinhas atéboazinhas. Aídesconserta o elástico das calcinhas. Eujá a ajudo a vestir pra ela não tirar mais. Mas ela tira" (P3, mãe de R).

Esta é outra situação frequente entre famílias de portadores de TOC: o paciente passa a não mais realizar certas tarefas consideradas simples, como, por exemplo, vestir-se, tomar banho, entre outras, o que leva seus familiares a executar essas tarefas por eles, reforçando ainda mais o sintoma (Guedes, 2001).

É importante lembrar que esses familiares, muitas vezes, tomam tais atitudes porque não estão esclarecidos sobre o que é o transtorno, ou mesmo porque pensam que, agindo dessa maneira, estarão ajudando o paciente (Silva, 2008). Guedes (2001, p. 65-66) afirma:

A ausência de suporte profissional específico para a família conduzà suposição de que ela age de maneira que não é planejada, sistemática e avaliada. Ao contrário, a ação da família é natural, intuitiva, inconsciente, emocional. Essa oposição de estilos de atuação reflete, como sugere Skinner, a oposição entre duas formas de controle: o comportamento governado por regras e o comportamento sob controle das contingências.

Isto significa que a família tende a agir sob controle das consequências imediatas da situação, isto é, em alguns momentos atende à demanda do paciente ou se antecipa a ele, pensando que com isto se livrará do incômodo (sendo reforçada negativamente e reforçando positivamente o paciente) e em outras situações o ignora. Ou seja, a família age em função de um conjunto de fatores e, em cada momento, alguém se sobressai pesando mais que os outros e determinando a atitude que a família vai tomar (Guedes, 2001).

Quanto à segunda temática (frequência com que os familiares modificaram sua rotina no último mês por causa dos comportamentos obsessivo-compulsivos de 
seu filho), das 56 respostas relacionadas a esse tema, mais uma vez, apenas 21,4\% diziam nunca haver modificação na rotina familiar. Das demais respostas, 78,6\% se referiam a haver mudanças na rotina familiar. Entre estas últimas, 28,6\% indicaram intensa modificação (muitas vezes ou sempre).

As alterações na rotina podem abranger pequenos ajustes dentro da casa como, por exemplo, manter os móveis sempre ordenados de determinada forma para satisfazer a compulsão do filho, na tentativa de diminuir sua ansiedade, ou mesmo alterações no esquema de trabalho ou lazer de toda a família (Ferrão, 2004). É comum, portanto, que aconteçam atritos entre os familiares, gerando stress. Um dos participantes diz:

Praviragora, pracá, eleficou deitado lá... Eu disse: rapaz... olha a hora! 'Não, daqui a pouco, daqui a pouco.' Quase em cima da hora que ele saiu. Eu não gosto de sair em cima da hora pra meus trabalhos, meus afazeres... De certo modo, me incomoda. Aíeu tenho que dar atenção pra ele. Eu tenho que dar atenção, certo? Então é, é estressante, muito! Eu tentei começar a fazer um mestrado e não tenho estrutura pra fazer um mestrado. Eu não tenho, não existe cabeça pra isso (P1, pai de C).

Este pai é tão afetado pelo transtorno do filho que chega a desistir de seus projetos pessoais. Este comportamento pode comprometer a sua própria saúde. Torresan et al. (2007, p.17) mostram que "Compaixão, vergonha, raiva e muita ambivalência são sentimentos comuns entre os familiares, cuja sobrecarga emocional pode ter efeitos deletérios na sua própria saúde mental".

Todas essas modificações no cotidiano familiar costumam causar desgaste não só para o próprio paciente, como para seus parentes. Esta foi a terceira temática analisada e, no que diz respeito a ela, verifica-se que 100\% das respostas indicaram desgaste na família, sendo 50\% em alto grau (muito ou muitíssimo). Como os comportamentos obsessivo-compulsivos são realizados repetidamente, mesmo que impliquem discussões ou danos materiais, é frequente que as pessoas ao redor de um portador de TOC vejam seus atos como algo desgastante.

O stress vivido por familiares de portadores de TOC muitas vezes provoca a redução de suas atividades sociais, acadêmicas ou profissionais, em função da dedicação ao cuidado com o doente (Ferrão, 2004). Os comentários dos participantes também ilustram bem esse ponto: "Quase não saio mais, eu fico muito ligada nele. Assim, depois que ele adoeceu, meu mundo mudou" (P2, mãe de $S$ ).

Um dos pais diz:

É um problema muito sério pra mim, porque eu, como pai, enfrentando esse problema, fico numa situação difícil. Então eu fico apreensivo, assim... Minha situação éficar apreensivo com o futuro dele. Eu me sinto constrangido, superconstrangido eaperreado demais. Eu me preocupo muito com isso que eu vejo. Tem momentos que eu fico, fico às vezes até sem dormir direito (P4, pai de F).

Uma mãe demonstra compreender a difícil situação que a filha vivencia e afirma que seu marido, pai da paciente, diz: "minha filha, deixe disso." E a filha responde: "mas pai, não é assim não, a coisa é difícil pra mim" (P3, mãe de R).

Vermes e Zamignani (2002) confirmam que essas situações são frequentes nas relações familiares em que há uma pessoa com TOC. Estes autores dizem:

Os membros da família relatam com frequência que diminuíram sensivelmente a vida social, o engajamento no trabalho, o sono e a qualidade de vida, por causa da convivência com os problemas decorrentes dos comportamentos obsessivo-compulsivos de um dos familiares (p.144).

Riquier (2004) também considera que existe uma forte correlação entre a organização familiar, a ansiedade e a cólera expressas pelo paciente. Em seu estudo, constatou que $60 \%$ dos membros da família participam dos rituais, tentando evitar para o paciente uma situação ansiogênica; 40,0\% efetuam os rituais; 19,0\% apenas controlam o familiar doente; quase 9,0\% têm suas atividades limitadas e 7,0\% tranquilizam a si mesmos sobre a ausência de riscos.

A quarta temática diz respeito ao grau de perturbação apresentado pelo portador de TOC quando seus pais não participam ou não se envolvem em comportamentos relacionados à doença, como rituais compulsivos e sintomas diversos.

Com relação a este tema, apenas 16,7\% das respostas indicaram nenhuma perturbação do paciente quando não atendido em suas solicitações. Isto significa que 83,3\% das respostas mostram o contrário. Destas últimas respostas, 26,2\% revelaram perturbação do paciente em níveis graves ou extremos. Guedes (2001) diz que uma das maneiras de identificar se o paciente 
fica mais nervoso é verificar se ele passa mais tempo realizando comportamentos relacionados aos sintomas quando não é assistido. Um dos pais entrevistados relata o seguinte:

E pra sair de manhã pro colégio está ficando difícil também, certo? Fica difícil, ele não sai na hora, chega um ponto que a gente tem que empurrar ele de dentro de casa prasair. Devezem quando ele chega aqui naquele estresse que ele está assim, muito nervoso, muito nervoso, está impaciente, ele fica se mexendo, se mexendo.... o queéque eu posso fazer? Posso fazer nada, cara. Ele quer sair, ele vaie volta pro banheiro... eu tenho que agarrar ele: vai fazer o que lá?, 'não, vou escovar.' De novo? É, várias vezes isso. Aíchega um ponto que eu fico na frente dele pra impedir que ele passe (P1, pai de C).

É comum que, para lidar com a doença, a família passe a adotar estratégias de enfrentamento, ou seja, maneiras de solucionar os problemas provocados pelos sintomas do TOC. Esse pai se sente incomodado pelos sintomas de seu filho e toma atitudes que visam forçá-lo a se comportar de maneira diferente. À primeira vista, esse tipo de estratégia de enfrentamento parece um tanto hostil, porém impedir alguém de completar um ritual obsessivo-compulsivo pode contribuir para a diminuição dos sintomas, sendo importante que se esclareça ao paciente o porquê deste impedimento.

Quando há uma interrupção do ritual obsessivo-compulsivo, a ansiedade do portador de TOC tende a aumentar, pois existe uma expectativa de que algo ruim poderá acontecer caso as compulsões não sejam realizadas. Mas, a partir do momento em que este paciente é exposto à situação que causa ansiedade e é impedido de realizar atos compulsivos por um período entre quinze minutos e três horas, ocorre um fenômeno chamado de habituação. Esta faz com que a ansiedade desapareça temporariamente, pois o indivíduo constata que suas expectativas catastróficas não se realizam. Assim, com a utilização regular desta técnica, os sintomas vão diminuindo em sua intensidade (Cordioli, 2004a).

Na busca por tratamento que alivie os sintomas do paciente, os pais muitas vezes perdem a esperança diante da resistência à mudança que esses comportamentos apresentam. Um dos entrevistados diz:

Não vejo solução. A gente já vem batalhando, bataIhando, vários psicólogos, terapeutas, ... psiquiatras, e, até hoje, nada de uma solução.... os médicos estão fazendo o possivel, mas também ninguém é Deus pra poder descobrir assim, uma fórmula instantânea pra curar. Mas fazem o possivel, cada um na suafunção, mas até agora... (P4, pai de F).

Outros já percebem algum resultado do tratamento para o transtorno do filho. "Ele está bem melhor do sintoma, né? O remédio tem dado resultado e a terapia" (P2, mãe de $S$ ).

Como o grupo de familiares aqui investigado já é atendido no setor de assistência a pessoas com Transtorno Obsessivo-Compulsivo de um hospital, é comum que estas pessoas também se refiram a estratégias de enfrentamento que envolvem a utilização de medicações ou psicoterapia. Como se pode depreender de suas falas, as opiniões dos familiares sobre a eficácia do tratamento por vezes divergem, de acordo com a gravidade dos sintomas apresentados pelo paciente.

\section{Consideração Finais}

Este estudo teve como objetivo compreender como a experiência da parentalidade é vivida por pessoas cujos filhos têm TOC, isto é, como é desempenhar a função de pai e mãe desses pacientes em relação aos sintomas da doença e ao grau de acomodação familiar. As principais conclusões são:

- Ainda é predominante a atribuição do papel de cuidador às mulheres. Neste estudo, os pacientes indicaram mais vezes a mãe como familiar mais próximo do que o pai (foram 12 mães e apenas 2 pais). Além disto, as mães alcançaram um maior escore na Medida de Criticismo Percebido (85,8\% das vezes) do que os pais (14,2\%). Isto demonstra a influência dos padrões culturais na diferenciação dos papéis ligados aos gêneros;

- A maior parte dos familiares de portadores de TOC (78,6\%) apresenta comportamentos relacionados ao fenômeno da acomodação familiar, participando da realização dos rituais dos pacientes com alta frequência;

- O transtorno também traz modificações à rotina da família em 78,6\% dos casos pesquisados, o que pode ser um fator correlacionado ao desgaste vivenciado pelos familiares. Todos eles afirmam que há desgaste na família e metade aponta que há muito ou muitíssimo desgaste;

- Verifica-se que 83,3\% dos pacientes perturbam os familiares quando não são atendidos em suas solicitações relacionadas aos sintomas do TOC. 
Como se pode ver, é grande o sofrimento que afeta toda a família de um paciente com TOC, principalmente aqueles que estão mais próximos, seus cuidadores, em geral mães ou pais. Deste modo, considera-se que esta pesquisa pode contribuir para ampliar o conhecimento sobre o tema e servir de apoio tanto para os profissionais que lidam com esta população quanto para os diretamente envolvidos, pacientes e seus familiares.

\section{Referências}

Almeida, L. S. (2007). Mãe, cuidadora e trabalhadora: as múltiplas identidades de mães que trabalham. Revista do Departamento de Psicologia UFF, 19 (2), 411-422. Recuperado em maio 22, 2008, disponível em http://www. scielo.br/scielo.php?script=sci_pdf\&pid=S0104$80232007000200011 \&$ lng=en\&nrm=iso\&tlng=pt

American Psychiatric Association. (2002). Diagnostic and statistical manual of mental disorders (DSM-IV) (4th ed.) Washington. Retrieved August 21, 2007, from http:// www.psiqweb.med.br/dsm/dsm.html

Calvocoressi, L., Lewis B., Harris M., Trufan S., Goodman W., McDougle C., \& Price, L. H. (1995). Family accommodation in obsessive-compulsive disorder. American Journal of Psychiatry, 152 (3), 441-443.

Cordioli, V. A. (2004a). Transtorno obsessivo-compulsivo. In P. Knapp (Org.), Terapia cognitivo-comportamental na prática psiquiátrica (pp.193-208). São Paulo: Artmed.

Cordioli, V. A. (2004b). Vencendo o transtorno obsessivocompulsivo. Porto Alegre: Artmed.

Costa, E. (2003). O corpo/identidade masculino nos cuidados da infância. Tese de doutorado não-publicada, Fundação Oswaldo Cruz, Rio de Janeiro. Recuperado em janeiro 25, 2008, disponível em www.cetrans.com.br/artigos/ Eduardo_Costa.pdf

Ferrão, Y. A. (2004). Características clínicas do transtorno obsessivo-compulsivo refratário aos tratamentos convencionais. Tese de doutorado não-publicada, Universidade de São Paulo. Recuperado em julho 22, 2008, disponível em http://protoc.incubadora.fapesp.br/portal/V.teses/ tese\%20Ygor\%20Ferrao.pdf

Guedes, M. L. (1997). Transtorno obsessivo-compulsivo: um estudo do processo de acomodação familiar. Dissertação de mestrado não-publicada, Universidade Federal de São Paulo.

Guedes, M. L. (2001). Relação família-paciente no transtorno obsessivo-compulsivo. Revista Brasileira de Psiquiatria, 23 (2), 65-67. São Paulo. Recuperado em novembro 14, 2007, disponível em http://www.scielo.br/scielo.php? script=sci_arttext\&pid=S1516-4462001000600019

Leahy, R. L., Mc Ginn, L. K., Busch, F. N., \& Milrod, B. L. (2007). Transtornos de ansiedade. In G. O. Gabbard, J. S. Beck \& J. Holmes (Orgs.), Compêndio de psicoterapia de Oxford (pp.192-226). Porto Alegre: Artmed.

Niederauer, K. G., Braga, D. T., Souza, F. P., Meyer, E., \& Cordioli, A. V. (2007). Qualidade de vida em indivíduos com transtorno obsessivo-compulsivo: revisão da literatura. Revista Brasileira de Psiquiatria, 29 (3), 271-278. Recuperado em julho 22, 2008, disponível em http:// www.scielo.br/scielo.php?script $=$ sci_arttext \&pid=S1516-44462007000300015\&lng=en\&nrm=iso

Organização Mundial de Saúde. (1993). Classificação de transtornos mentais e de comportamento da CID-10. Porto Alegre: Artes Médicas.

Rangé, B. (2003). Terapia cognitiva do transtorno obsessivocompulsivo (TOC). In R. M. Caminha, R. Wainer, M. Oliveira \& N. M. Piccoloto (Orgs.), Psicoterapias cognitivo-comportamentais (pp.145-153). São Paulo: Casa do Psicólogo.

Riquier, F. (2004) Trouble anxieux et famille: le modèle du trouble obsessionnel compulsif. Revue Médicale Suisse, 62 (2496), 1781-1785

Santos, V., \& Candeloro, R. J. (2006). Trabalhos acadêmicos: uma orientação para a pesquisa e normas técnicas. Porto Alegre: AGE.

Severino, A. J. (2007). Metodologia do trabalho científico. São Paulo: Cortez.

Silva, R. R. (2008). Um estudo sobre a relação família-paciente com transtorno obsessivo-compulsivo. Dissertação de mestrado não-publicada, Universidade Católica de Pernambuco, Recife.

Steketee, G., \& van Noppen, B. (2003). Family approaches to treatment for obsessive compulsive disorder. Revista Brasileira de Psiquiatria, 25 (1),43-50. Recuperado em agosto 7, 2007, disponível em http://www.scielo.br/ scielo.php?Script=sci_arttext\&pid=S1516-444620000 01000 09\&lng=en\&nrm=iso

Sukhodolsky D. G., Rosario-Campos M. C., Scahill L., Katsovich L., Pauls D. L., Peterson B. S., et al. (2005). Adaptive, emotional, and family functioning of children with obsessive-compulsive disorder and comorbid attention deficithyperactivity disorder. American Journal of Psychiatry, 162 (6), 1125-1132. Retrieved April 24, 2009, from http:// ajp.psychiatryonline.org/cgi/reprint/162/6/1125

Torresan, R. C., Smaira, S. I., Ramos-Cerqueira, A. T. A., \& Torres, A. R. (2008). Qualidade de vida no transtorno obsessivo-compulsivo: uma revisão. Revista de Psiquiatria Clínica, 35 (1), 13-19. Recuperado em julho 22, 2008, disponível em http://www.scielo.br/scielo.php? script=sci_arttext\&pid=S0101-60832008000100 003\&lng $=e n \& n r m=i s o$

Torres, A. R., \& Lima, M. C. P. (2005). Epidemiology of obsessive-compulsive disorder: a review. Revista Brasileira de Psiquiatria, 27 (3), 237-242. Retrieved July 22, 2008, from http://www.scielo.br/scielo.Php?script=sci_arttext \&pid=\$1516-44462005000300015\&lng=en\&nrm=iso

Vermes, J. S., \& Zamignani, D. R. (2002). A perspectiva analítico-comportamental no manejo do comportamento obsessivo-compulsivo: estratégias em desenvolvimento. Revista Brasileira de Terapia Comportamental e Cognitiva, 4 (2), 135-149. Recuperado em janeiro 25, 2008, disponível em http://scielo.bvs-psi.org.br/scielo. php? pid=S1517-55452002000200006\&script=sci_art text

Recebido em: 14/8/2008

Versão final reapresentada em: 27/5/2009

Aprovado em: 23/9/2009 